\title{
REMOTE SENSING OF THE CRYOSPHERE IN HIGH MOUNTAIN ASIA
}

\author{
Batuhan Osmanoglu', Thomas H. Painter ${ }^{2}$, David Shean ${ }^{3}$, Anthony Arendt ${ }^{3}$, Jeffrey Kargel ${ }^{4}$, \\ Steven A. Margulis ${ }^{5}$ \\ ${ }^{1}$ NASA Goddard Space Flight Center, Greenbelt, MD 20771 USA \\ ${ }^{2}$ Jet Propulsion Laboratory, 4800 Oak Grove Drive, Pasadena, CA 91109 USA \\ ${ }^{3}$ Applied Physics Laboratory, University of Washington, Seattle, WA 98115 USA \\ ${ }^{4}$ Department of Hydrology and Atmospheric Sciences, University of Arizona, Tucson, AZ 85721 USA \\ ${ }^{5}$ Dept. of Civil and Environmental Engineering, University of California, Los Angeles, CA 90095 USA
}

\begin{abstract}
High Mountain Asia (HMA), often referred to as the "third pole" of the world because its high elevation glaciers, contains the largest amount of fresh water outside the polar ice sheets. The region's hydrology is strongly controlled by variations in the timing and distribution of runoff from snow and glacier melt. Recent improvements in remote sensing technologies and atmospheric / land surface models provides new approaches for assessing the HMA cryosphere. A recently-funded NASA program aims to apply these tools to advance understanding of HMA cryospheric processes. Here we present an overview of planned team activities during the three-year project.
\end{abstract}

Index Terms - High Mountain Asia, Glaciers, Cryosphere, Remote Sensing

\section{INTRODUCTION}

High Mountain Asia (HMA), extending from the Hindu Kush and Tien Shan in the west to the eastern Himalaya, is one of the world's largest reservoirs of perennial glaciers, snow, and permafrost outside of the Earth's polar ice sheets (Figure 1) [1]. Water derived from melting of these snow and ice masses contributes to fulfilling the water needs of over one billion people in the region [2]. Changes in the region's climate and runoff regime have altered this water supply, while also transforming regional ecology, land utilization practices, and the hazards associated with landslides and glacial-lake-outburst floods [3]. Future changes in glacier runoff due to climate change will influence food and water security in the HMA [4], emphasizing the need for improved quantification of hydrological changes for policy decisions and resource management.

There is considerable variability in the partitioning of runoff contributions between snowmelt, glacier melt, and rainfall in the HMA region. For example, the high alpine regions of the western Himalaya see greater impacts of glacier variations on streamflow than in the eastern HMA where monsoon rains dominate the hydrograph [5]. High erosion rates across the HMA contribute to considerable debris cover on glacier surfaces, which complicates the glacier modeling. Black carbon (BC) and dust deposition on glacier and snowpack surfaces is occurring in greater quantities across the HMA and have significant impacts on the surface energy budget with unknown contribution relative to greenhouse gas warming.

A new program recently funded under NASA Earth Sciences aims to use remote sensing datasets to study these cryospheric processes over the HMA region. This will be accomplished through the integration of modeling, remote sensing, and in situ observations. Key scientific objectives include the partitioning of the HMA water balance (rainfall, snowmelt, glacier melt and groundwater), estimating spatial and temporal variability in past and projected future cryospheric changes, and assessing the downstream impacts of hydrological changes on ecosystems and infrastructure.

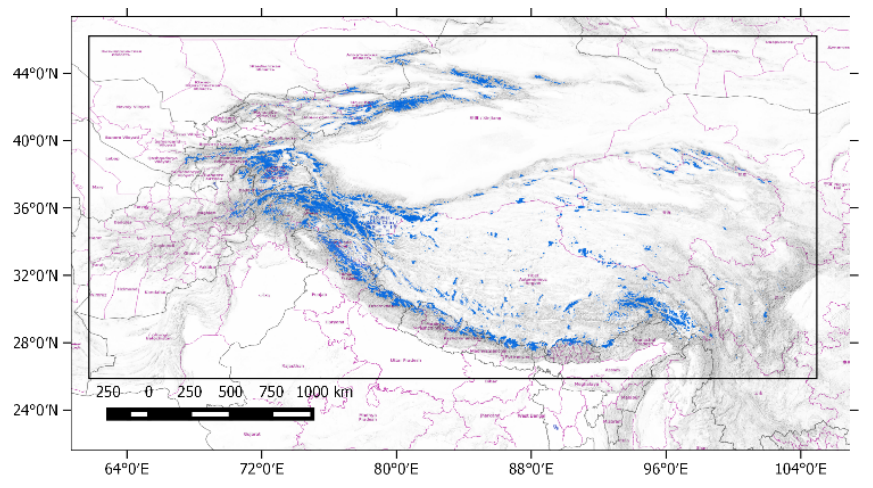

Figure 1 High Mountain Asia (HMA) study region (black rectangle) and glacier cover (blue polygons [6]).

\section{REMOTE SENSING MEASUREMENTS}

Data from multiple sensors will be used to assess past and ongoing changes in surface elevation, land surface conditions and mass of the HMA cryosphere. 


\subsection{Height}

\subsubsection{Historical Imagery and HRSI}

A large subset of glaciers distributed across HMA will be analyzed for volume change by differencing DEMs that will be derived from declassified historical imagery and HRSI starting from the 1970's with the historical imagery and covering a time period between 2002 and 2016 for HRSI (Figure 2). Hexagon imagery from the 1970's has currently been processed for 500 glaciers in the Himalayan region and 750 glaciers in the Karakoram and Hindu Kush regions. In combination with the ASTER and HRSI scenes, this will provide more than forty years of geodetic mass balance changes in HMA [7]. NASA's access to commercial HRSI data (e.g., DigitalGlobe's Worldview satellites), cluster computing, and automated stereogrammetric routines available from the Ames Stereo Pipeline (ASP) software will provide surface elevations at sub-meter resolution [8], [9]. These data have been used to estimate $(\sim 0.5 \mathrm{~m} / \mathrm{pixel})$ elevations for a variety of surfaces, including those with snow and ice cover, with vertical and horizontal accuracies $<3.5 \mathrm{~m}$ [9]. Even though the historical imagery does not come with satellite ephemeris, a new automated DEM extraction routine can generate DEMs with $\sim 5 \mathrm{~m}$ accuracy [10].

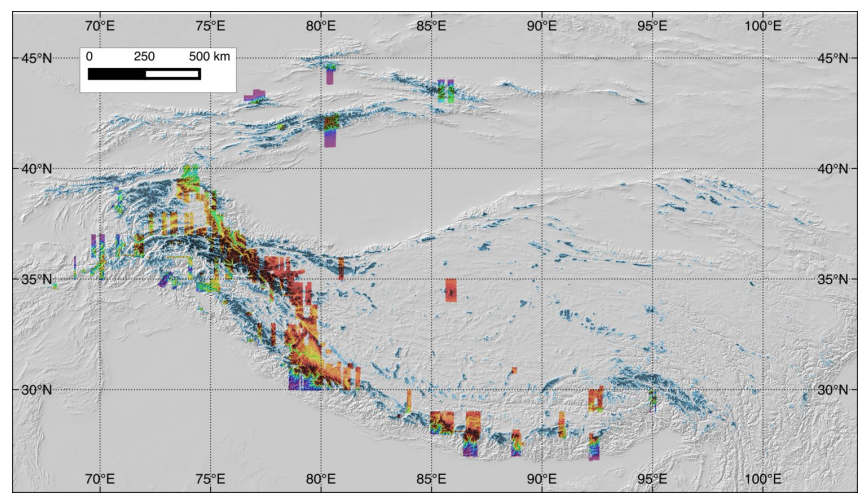

Figure 2 Completed processing of DigitalGlobe DEMs as of 7Jan-2017 (colored grids). Blue polygons represent HMA glaciers [6].

\subsubsection{Satellite Interferometry}

Satellite radar interferometry has been used for DEM generation for over three decades now providing high resolution $(\sim 10-20 \mathrm{~m})$ DEMs independent of atmospheric conditions and sunlight. Due to their short temporal decorrelation period, DEM generation over snow and ice covered surfaces require short repeat intervals [11]. Recent bistatic (TanDEM-X) and short repeat pass SAR constellations (Sentinel-1, Cosmo Skymed) allow high accuracy DEMs to be generated over glaciers. In addition to regular interferometry with TanDEM-X data, the project will also use its derived product, the WorldDEM, where it is available.

\subsubsection{LIDAR Altimetry}

Data from NASA's Ice, Cloud and Elevation Satellite (ICESat) have been the primary source of information about region-wide changes in the mass balance of HMA glaciers [12]. These data will be used by HiMAT to validate glacier mass balance models and to provide topographic control over non-glacier surfaces for the HRSI and SAR analysis [7]. Data from future NASA satellite lidar missions including ICESat-2 and the Global Ecosystem Dynamics Investigation (GEDI) Lidar will provide elevation data at higher resolution than ICESat and will be valuable tools for assessing recent glacier changes.

\subsection{Coverage}

\subsubsection{Fractional snow and ice cover and grain size}

Data from the NASA Moderate Resolution Spectroradiometer (MODIS- $500 \mathrm{~m}$ ), NPP Visible Infrared Imaging Radiometer Suite (VIIRS - $750 \mathrm{~m}$ ), and the Landsat 8 Operational Land Imager (OLI - $30 \mathrm{~m}$ ) will be leveraged to produce daily to 16-day fractional snow- and ice-covered area with the Snow Covered Area and Grain size (e.g. MODSCAG) algorithm [13]. Each of these uses the same spectral mixture analysis of the visible through shortwave infrared wavelength spectra with grain sizeresolved radiative transfer modeling to quantitatively determine fractional cover [14] and the associated snow grain size, from which we can map to snow albedo. In turn, the time series of the daily products from MODIS and VIIRS are used in the MODICE/VIIRSICE processing to generate annually resolved minimum exposed snow and ice [15]. These products will be used to validate modeling of the cryosphere.

\subsubsection{Radiative Forcing by Impurities in Snow}

Dust and BC deposition to snow and ice in the HMA has increased markedly in the Anthropocene from increases in land disturbance and industrialization/biomass burning. The multispectral sampling of MODIS, VIIRS, and OLI allow us to infer radiative forcing by dust and $\mathrm{BC}$ in snow [16]. With these products, we can either validate aerosol transport and radiative transfer modeling of radiative properties of the cryosphere or provide modeling constraint to which transport and RT modeling must be forced. These products are generated and used to allow us to understand the controls on melting of snow and ice in HMA.

\subsubsection{Debris Cover Mapping}

Many HMA glaciers are heavily debris-covered typically reducing thinning rates compared to bare ice areas, although some studies have shown similar thinning rates over debriscovered and debris-free areas [17]. Debris cover maps can be used to derive melt relations of glaciers expressing debris cover percentage as a function of cumulative area [18]. Debris cover can be mapped using optical data. Clean glacier surface is very reflective from visible to nearinfrared (NIR) wavelength (0.4-1.4 $\mu \mathrm{m})$, and has a low reflectivity in the short wave infrared (SWIR) region (1.4$2.5 \mu \mathrm{m})$. Several band-ratios have been developed to take 
advantage of this characteristic [18]-[20]. Available DEMs, glacier outlines and data from ASTER and Landsat will be used to map debris cover over the HMA region.

\subsection{Mass}

\subsubsection{Snow Water Equivalent}

Measurements of snow water equivalent (SWE) are needed to calibrate runoff models, but SWE is very difficult to measure using remote sensing products alone. Passive microwave datasets will be used as a starting point to estimate SWE based on the brightness temperature of snow surfaces using forward modeling approaches [21]. These data are available at relatively coarse resolution, and have limitations over deep snowpacks, when the snowpack is wet or has internal ice layering. To address these challenges, both fSCA observations (Section 2.2.1) and passive microwave SWE estimates, will be assimilated into a high resolution reanalysis framework in order to improve initial estimates of SWE derived from a land surface model. Passive microwave observations will also be used assess freeze/thaw transitions [22] which will inform assessments of soil melting and freezing processes.

\subsubsection{GRACE}

Data from the NASA/DLR Gravity Recovery and Climate Experiment (GRACE) provide direct measurements of time variable mass changes at monthly temporal and approximately $300 \mathrm{~km}$ spatial resolution. For cryospheric studies, GRACE data can be used as a direct measure of snow and ice mass balance, providing a distinct advantage over altimetric methods which require assumptions about the density of the changing ice volume. A challenge of using GRACE to study the cryosphere is that the satellites observe all components of the Earth's hydrographic and geophysical signals, requiring careful partitioning of the various signals. This is a particular challenge in the HMA region due to the blending of mass change signals from numerous hydrological (precipitation, cryosphere), geophysical (glacial isostatic adjustment and fault tectonics) and human (land use change and irrigation) signals [23]-[25].

HiMAT will use GRACE data extensively in validating remote sensing and model assessments of the HMA water balance. Various approaches will be tested, including a comparison of the GRACE least-squares mascon product [24] with ensemble estimates of glacier mass balance and other hydrological changes. A second approach will involve forward modeling of water balances estimates as part of the Level 1B GRACE data reduction [26]. This will provide a mechanism for iteratively assessing the quality of various models and remote sensing assessments generated by HiMAT, providing important validation for regional-scale assessments.

\section{IMPACT ASSESSMENTS \\ 3.1. Cryospheric Hazards}

Due to its high relief and the situation of human settlements in alpine regions, the HMA is particularly susceptible to hazards associated with cryospheric processes (e.g. [27]). These include glacial lake outburst floods, landslides and avalanches. HiMAT will use optical satellite imagery (Landsat, ASTER and WorldView) to build inventories of glacial lake, moraine dam and glacier/snowpack evolution and use both satellite optical imaging and in situ observations of glacial lakes to constrain analytical models of the lakes' effects on glacier melting. These datasets will inform models that provide decision support and hazard mapping for communities living in the region.

Retreat and thinning of glaciers constitute a chief dynamic component of the integrated Earth system and is causing a changing hazard landscape. In some places we may presume that disappearing ice may ease the hazard environment, but in many other places hazards increase as glacier lakes form and grow and the threat of glacier lake outburst floods increases, and as debuttressing of unstable ice and moraine masses and fractured bedrock causes an increased hazard due to landslides and ice avalanches. Furthermore, the rapid increase in hydroelectric power development, mountain tourism, and local populations in many high mountain valleys is causing a dramatic increase in the exposure and value at risk, hence in the integrated risk.

\subsection{Downstream Impacts}

The livelihoods of communities living downstream from the HMA region are impacted by variations in the timing and magnitude of streamflow. HiMAT will use a series of economic valuation models to predict the impact of various climate change scenarios on the potential for hydropower generation, and on the health of fisheries and wetlands that receive freshwater inputs from glacier and snow melt.

\section{CONCLUSIONS}

Remote sensing measurements from a variety of sensors will be used to improve our understanding of the world's largest reservoir of perennial glaciers and snow outside of the Earth's polar ice sheets. Satellite remote sensing of HMA will not only provide an opportunity to monitor the ongoing changes in the region, but will also assist in calibration and validation of models which will be used to shed light to the future changes. Improved regional forecasts will be used to address the vulnerabilities of humans and the environment living downstream of the glaciers.

\section{REFERENCES}

[1] A. Grinsted, "An estimate of global glacier volume," The Cryosphere, vol. 7, no. 1, p. 141, 2013.

[2] W. W. Immerzeel, L. P. H. van Beek, and M. F. P. Bierkens, "Climate Change Will Affect the Asian Water Towers," Science, vol. 328, no. 5984, pp. 1382 1385, Jun. 2010. 
[3] T. Bolch et al., "The State and Fate of Himalayan Glaciers," Science, vol. 336, no. 6079, pp. 310-314, Apr. 2012.

[4] A. F. Lutz, W. W. Immerzeel, P. D. A. Kraaijenbrink, A. B. Shrestha, and M. F. P. Bierkens, "Climate Change Impacts on the Upper Indus Hydrology: Sources, Shifts and Extremes," PLOS ONE, vol. 11, no. 11, p. e0165630, Nov. 2016.

[5] A. F. Lutz, W. W. Immerzeel, A. B. Shrestha, and M. F. P. Bierkens, "Consistent increase in High Asia's runoff due to increasing glacier melt and precipitation," Nat. Clim. Change, vol. 4, no. 7, pp. 587-592, Jun. 2014.

[6] W. T. Pfeffer et al., "The Randolph Glacier Inventory: a globally complete inventory of glaciers," J. Glaciol., vol. 60, no. 221, pp. 537-552, 2014.

[7] J. Maurer and S. Rupper, "Tapping into the Hexagon spy imagery database: A new automated pipeline for geomorphic change detection," ISPRS J. Photogramm. Remote Sens., vol. 108, pp. 113-127, 2015.

[8] C. S. Neigh, J. G. Masek, and J. E. Nickeson, "Highresolution satellite data open for government research," Eos Trans. Am. Geophys. Union, vol. 94, no. 13, pp. 121-123, 2013.

[9] D. E. Shean et al., "An automated, open-source pipeline for mass production of digital elevation models (DEMs) from very-high-resolution commercial stereo satellite imagery," ISPRS J. Photogramm. Remote Sens., vol. 116, pp. 101-117, Jun. 2016.

[10] J. M. Maurer, S. B. Rupper, and J. M. Schaefer, "Quantifying ice loss in the eastern Himalayas since 1974 using declassified spy satellite imagery," The Cryosphere, vol. 10, no. 5, pp. 2203-2215, Sep. 2016.

[11] B. Osmanoğlu, M. Braun, R. Hock, and F. J. Navarro, "Surface velocity and ice discharge of the ice cap on King George Island, Antarctica," Ann. Glaciol., vol. 54, no. 63, pp. 111-119, Jul. 2013.

[12] A. S. Gardner et al., "A Reconciled Estimate of Glacier Contributions to Sea Level Rise: 2003 to 2009," Science, vol. 340, no. 6134, pp. 852-857, May 2013.

[13] T. H. Painter, K. Rittger, C. McKenzie, P. Slaughter, R. E. Davis, and J. Dozier, "Retrieval of subpixel snow covered area, grain size, and albedo from MODIS," Remote Sens. Environ., vol. 113, no. 4, pp. 868-879, Apr. 2009.

[14] K. Rittger, T. H. Painter, and J. Dozier, "Assessment of methods for mapping snow cover from MODIS," $A d v$. Water Resour., vol. 51, pp. 367-380, Jan. 2013.

[15] T. H. Painter, M. J. Brodzik, A. Racoviteanu, and R. Armstrong, "Automated mapping of Earth's annual minimum exposed snow and ice with MODIS," Geophys. Res. Lett., vol. 39, no. 20, Oct. 2012.

[16] T. H. Painter, A. C. Bryant, and S. M. Skiles, "Radiative forcing by light absorbing impurities in snow from MODIS surface reflectance data," Geophys. Res. Lett., vol. 39, no. 17, p. n/a-n/a, Sep. 2012.
[17] J. Gardelle, E. Berthier, Y. Arnaud, and A. Kaab, "Region-wide glacier mass balances over the PamirKarakoram-Himalaya during 1999-2011 (vol 7, pg 1263, 2013)," Cryosphere, vol. 7, no. 6, pp. 18851886, 2013.

[18] C. Kienholz, S. Herreid, J. L. Rich, A. A. Arendt, R. Hock, and E. W. Burgess, "Derivation and analysis of a complete modern-date glacier inventory for Alaska and northwest Canada," J. Glaciol., vol. 61, no. 227, pp. 403-420, 2015.

[19] L. M. Andreassen, F. Paul, A. Kääb, and J. E. Hausberg, "Landsat-derived glacier inventory for Jotunheimen, Norway, and deduced glacier changes since the 1930s," The Cryosphere, vol. 2, no. 2, pp. 131-145, 2008.

[20] H. Alifu, R. Tateishi, and B. Johnson, "A new band ratio technique for mapping debris-covered glaciers using Landsat imagery and a digital elevation model," Int. J. Remote Sens., vol. 36, no. 8, pp. 2063-2075, 2015.

[21] B. A. Forman and R. H. Reichle, "Using a Support Vector Machine and a Land Surface Model to Estimate Large-Scale Passive Microwave Brightness Temperatures Over Snow-Covered Land in North America," IEEE J. Sel. Top. Appl. Earth Obs. Remote Sens., vol. 8, no. 9, pp. 4431-4441, Sep. 2015.

[22] E. Podest, K. C. McDonald, and J. S. Kimball, "Multisensor Microwave Sensitivity to Freeze/Thaw Dynamics Across a Complex Boreal Landscape," IEEE Trans. Geosci. Remote Sens., vol. 52, no. 11, pp. 6818 6828, Nov. 2014.

[23] K. Matsuo and K. Heki, "Time-variable ice loss in Asian high mountains from satellite gravimetry," Earth Planet. Sci. Lett., vol. 290, no. 1-2, pp. 30-36, Feb. 2010.

[24] T. Jacob, J. Wahr, W. T. Pfeffer, and S. Swenson, "Recent contributions of glaciers and ice caps to sea level rise," Nature, vol. 482, no. 7386, pp. 514-518, Feb. 2012.

[25] S. Yi and W. Sun, "Evaluation of glacier changes in high-mountain Asia based on 10 year GRACE RL05 models," J. Geophys. Res. Solid Earth, vol. 119, no. 3, pp. 2504-2517, Mar. 2014.

[26] S. B. Luthcke, T. J. Sabaka, B. D. Loomis, A. A. Arendt, J. J. McCarthy, and J. Camp, "Antarctica, Greenland and Gulf of Alaska land-ice evolution from an iterated GRACE global mascon solution," $J$. Glaciol., vol. 59, no. 216, pp. 613-631, Aug. 2013.

[27] J. S. Kargel et al., "Geomorphic and geologic controls of geohazards induced by Nepal's 2015 Gorkha earthquake," Science, vol. 351, no. 6269, p. aac8353, 2016. 